\title{
Best Disease Presenting as Subretinal Pigment Epithelium Hyperreflective Lesion on Spectral-Domain Optical Coherence Tomography: Multimodal Imaging Features Multimodal imaging in Best disease
}

Isil Sayman Muslubas

Istanbul Retina Institute

Serra Arf

Istanbul Retina Institute

Mumin Hocaoglu

Istanbul Retina Institute

M. Giray Ersoz

Istanbul Retina Institute

Murat Karacorlu ( $\square$ mkaracorlu@gmail.com)

Istanbul Retina Institute

\section{Research Article}

Keywords: Best disease, optical coherence tomography, optical coherence tomography angiography, quiescent neovascularization, subretinal pigment epithelium hyperreflective lesion

Posted Date: June 17th, 2021

DOI: https://doi.org/10.21203/rs.3.rs-543424/v1

License: () (1) This work is licensed under a Creative Commons Attribution 4.0 International License. Read Full License 


\section{Abstract}

Purpose

To report clinical and multimodal imaging features of Best disease in patients presenting with subretinal pigment epithelium hyperreflective lesion.

Design

Retrospective study.

Methods

Clinical examination findings and multimodal imaging features, including color fundus photography, spectral-domain optical coherence tomography (SDOCT), fundus autofluorescence, fluorescein and indocyanine green angiography (ICGA), and optical coherence tomography angiography (OCTA) images were evaluated retrospectively.

Results

We assessed 27 eyes of 16 patients with the diagnosis of Best disease. Only patients presenting with serous macular detachment and subretinal pigment epithelium hyperreflective lesion in one or both eyes were included in this study. In 17 of 27 eyes (63\%), fibrosis was identified by multimodal imaging techniques. Although there was no sign of active neovascularization on fundus examination or SD-OCT, a vascular network could be identified in 7 eyes (26\%) (in 1 eye with OCTA only and in 6 with both OCTA and ICGA). Active neovascularization was seen in 3 eyes (11\%). Treatment was recommended for eyes with active neovascularization, and follow-up was scheduled for eyes with quiescent neovascularization and fibrosis.

Conclusion

Eyes with Best disease with subretinal pigment epithelium hyperreflective lesion and serous macular detachment may show fibrosis, quiescent neovascularization, or active neovascularization. Multimodal imaging techniques are very important for differentiation of these lesions.

\section{Introduction}

Vitelliform macular dystrophy, also called Best disease, is an inherited retinal dystrophy caused by mutation in the BEST1 gene located on chromosome 11q12-q13. Although five stages have been described, including previtelliform (stage I), vitelliform (stage II), pseudohypopyon (stage III), vitelliruptive (stage IV), and atrophic (stage V), the disease does not progress through each of these stages in every individual.[1-2] Indeed, the vitelliform stage, in which the macula has a characteristic yellowish appearance due to lipofuscin accumulation at the level of the retinal pigment epithelium (RPE), is frequently not present at the time of examination and sometimes it never occurs.[1-3]

Especially during the vitelliform stage, diagnosis of Best disease is simple. However, during late stages, confirming the diagnosis by multimodal imaging techniques such as optical coherence tomography (OCT) and fundus autofluorescence is very useful.[4] Subretinal fibrosis and neovascularization are known as late-stage complications of the disease. Fibrotic scarring and choroidal neovascularization have similar presentation and they should be distinguished from each other.[3-4] Optical coherence tomography angiography (OCTA), which has become increasingly a useful and minimally invasive tool for monitoring new vessels, is a preferred imaging technique along with fluorescein angiography (FA) and indocyanine green angiography (ICGA).[5-6] An abnormal electrooculogram (EOG) with a low Arden ratio and family history are helpful in supporting the diagnosis.[1,3]

Although the appearance of lipofuscin accumulation between the RPE and the outer retina is very characteristic of Best Disease, presence of hyperreflective material between the RPE and Bruch's membrane, with serous macular detachment, may be the first presenting finding in some patients. The diagnosis can be controversial in such cases. In this study we aimed to report clinical and multimodal imaging features of patients with Best disease presenting with a hyperreflective RPE elevation and serous macular detachment.

\section{Methods}

Patients with Best disease who had been diagnosed at Istanbul Retina Institute between January 2008 and December 2019 were evaluated retrospectively. Twenty-seven eyes of 16 patients presenting with a hyperreflective RPE elevation and serous macular detachment associated with Best disease were included in this study. Written informed consent was obtained prior to the diagnostic and therapeutic procedures. The study protocol was approved by the Institutional Review Board of Şişli Memorial Hospital, Istanbul. The study adhered to the tenets of the Declaration of Helsinki.

The initial diagnosis was based on clinical examination and spectral-domain OCT (SD-OCT) assessment. If fundus examination revealed an elevated hyperreflective lesion, further examination by OCT was required. Presence of hyperreflective material between the RPE and Bruch's membrane with serous macular detachment on SD-OCT were considered as inclusion criteria.

For all patients, medical record data, including measurement of best corrected visual acuity (BCVA) by the Early Treatment Diabetic Retinopathy Study chart, refraction, intraocular pressure measured by applanation tonometer, detailed anterior segment and fundus examination by slit-lamp biomicroscopy with a 90 diopter noncontact lens, and multimodal imaging features, were collected and analyzed.

The Spectralis OCT system (Heidelberg Engineering, Heidelberg, Germany) was used for fundus autofluorescence, macular scans, digital fluorescein angiography, and ICGA, and images were obtained by a single examiner experienced in performing scans using the SD-OCT device.

Page $2 / 11$ 
Patients identified by SD-OCT as having serous macular detachment and subretinal hyperreflective material underwent OCTA between March 2017 and November 2019. OCTA images were obtained by using the AngioVue (Optovue) OCTA system on a commercially available SD-OCT device (RTVue XR Avanti, Optovue, Fremont, CA, USA). The OCTA images were evaluated by using split-spectrum amplitude-decorrelation angiography (SSADA) and an algorithm to visualize retinal and choroidal vasculature in a $6 \times 6 \mathrm{~mm}$ volume of the central part of the retina. The retina was scanned in both horizontal and vertical axes, with correction for movements of the eyes. Automatic segmentation of the retinal layers was performed by the viewing software and was used to generate en face projection images of the lesion. In the case of segmentation errors, the segmentation lines were manually adjusted to evaluate the lesion adequately. Images with signal strength index less than 40 were considered poor-quality images and excluded from the study.

The diagnosis was confirmed by hyperautofluorescent material on fundus autofluorescence imaging in both eyes, an abnormal EOG with a low Arden ratio, and presence of a family history in the remaining 14 patients. Presence of hemorrhage on fundus examination, intraretinal fluid or subretinal hyperreflection above the RPE elevation or irregular RPE elevation on SD-OCT with or without increased hyperfluorescence on fluorescein angiography, and an early network with late staining plaque on ICGA were considered signs of active neovascularization. Only the presence of a vascular network on OCTA or FA and ICGA without signs of active neovascularization was accepted as quiescent neovascularization. ${ }^{5}$ Serous macular detachment was not accepted as a sign of active neovascularization because it could also be a primary result of Best disease. The maximum height of a hyperreflective lesion was defined as the maximum distance between the RPE and Bruch's membrane. Manual calipers provided with the software of the device were used for measurement. Values for each measurement were obtained from horizontal and vertical line scans, and values were averaged

Eyes with an any evidence of other retinal disorders, a history of previous treatment with antivascular endothelial growth factor, or photodynamic treatment were excluded from the study. Demographic and clinical data were collected from the medical chart, and data for all 27 eyes were used for statistical analysis. Descriptive statistical methods (mean, standard deviation) were used for characteristics such as age and sex. Wilcoxan signed rank test was used to compare first and last examination findings. Measurement values of the groups for continuous variables were compared using the Kruskal-Wallis test or Mann-Whitney $\mathrm{U}$ test and for categorical variables were compared using chi-square test. Statistical analyses used SPSS Version 20.0 (SPSS Inc, Chicago, IL, USA). $P<0.05$ was considered statistically significant.

\section{Results}

Twenty-seven eyes of 16 patients were appropriate to include in this study. Twelve ( $75 \%$ ) were male. The age at first examination was $22.7 \pm 12.6$ years (range, 7-44 years). The mean initial logMAR visual acuity was $0.44 \pm 0.31$ (range, 1-0 logMAR). The mean initial height of hyperreflective lesion was $289.8 \pm 183.4 \mathrm{~mm}$ (range 100 to $791 \mathrm{~mm}$ ). Detailed demographic and clinical characteristics of patients are shown in Table 1.

At presentation, bilateral serous macular detachment and a hyperreflective lesion in the sub-RPE were identified in 11 patients (69\%). In the remaining 5 patients, vitelliform-stage disease was found in one patient's fellow eye (6\%) (patient 10), and vitelliruptive-stage disease in 4 patients' fellow eyes (25\%) (patients 2, 9, 12, and 14). After detailed examination of patients with hyperreflective lesion, active neovascularization was identified in 2 eyes of 2 patients (patients 5 and 7) by both dye-based angiography and OCTA. Quiescent neovascularization was detected in 3 eyes of 2 patients (patients 3 and 11) by dyebased angiography alone, and was identified in 3 eyes of 2 patients (patients 7 and 15) by both dye-based angiography and OCTA. However, 3 patients (patients 1,2, and 6) did not have dye-based angiography or OCTA at the first examination, so presence of a vascular network inside the hyperreflective lesion could not be evaluated in 5 eyes, but OCTA assessment was performed at the final examination. No neovascular network was detected in 3 eyes of 2 patients (patients 1 and 2), but neovascularization was identified in both eyes of patient 6 (Figure 1).

Thirteen eyes of 8 patients were followed up for 1 to 11 years after diagnosis. Neovascularization developed in only one eye (patient 6 ) after 6 years of followup and the hyperreflective lesion was stable in the remaining 12 eyes. At last follow-up, the mean logMAR visual acuity was $0.45 \pm 0.27$ (range, $1-0$ logMAR) for those stable 12 eyes and there was no statistical difference in visual acuity between presentation and last follow-up ( $P=0.60)$. The mean height of the hyperreflective lesion was $333 \pm 3 \mathrm{~mm}$ (range 170 to $650 \mathrm{~mm}$ ), and there was also no statistical difference in the height of the lesion between presentation ( $(330 \pm 7 \mathrm{~mm}$ (range 175 to $650 \mathrm{~mm}$ ) and last follow-up $(P=0.09)$. As expected, the logMAR visual acuity had decreased, from 0.1 to 0.5 , and the height of lesion had increased, from 100 to $128 \mathrm{~mm}$, in the eye developing neovascularization. Figures 2 and 3 show images from patients 14 and 2 to indicate how the patient's retinal status remained unchanged during 1-year and 11-year follow-up, respectively.

At last evaluation, fibrosis was identified in 17 eyes (63\%) by multimodal imaging. Although there was no sign of active neovascularization on fundus examination or SD-OCT, a vascular network could be identified in 7 eyes (26\%) (in 1 eye only with OCTA and in 6 eyes with both OCTA and ICGA). Active neovascularization was seen in 3 eyes (11\%). Treatment was recommended for eyes with active neovascularization, and follow-up was scheduled for eyes with quiescent neovascularization and fibrosis. Figure 4 shows images from patient 7 to demonstrate quiescent neovascularization in 1 eye and active neovascularization in the fellow eye.

\section{Multimodal imaging features of patients}

On fundus examination, all eyes demonstrated serous macular detachment, vitelliform accumulation at the posterior pole, and central macular elevation. In eyes with active neovascularization, hemorrhage was also seen. On SD-OCT, regular and hyperreflective RPE elevation in 24 eyes (89\%), and a hyporeflective subretinal space were identified in all eyes (100\%). Outer retinal damage was seen in 7 eyes (26\%) of 6 patients, and choroidal excavation in 8 eyes (30\%) of 7 patients. However, all 3 eyes with active neovascularization had intraretinal fluid and irregular RPE elevation, and 2 eyes had also subretinal hyperreflectivity above the RPE elevation. Fundus autofluorescence images identified hyperautofluorescence due to lipofuscin accumulation at the posterior pole in all eyes. The hyperreflective RPE elevations were hypoautofluorescent due to fibrosis and scarring in 21 eyes (78\%) and related to neovascularization in 3 eyes (11\%), and were hyperautofluorescent in the remaining 3 eyes (11\%). Dye-based angiography was performed in 17 eyes (65\%). Nine eyes with only regular and 
hyperreflective RPE elevation demonstrated early hypofluorescence and late hyperfluorescence related to staining on FA and hypofluorescence on ICGA. Six eyes with quiescent neovascularization showed a late-phase ill-defined hyperfluorescence on FA without pooling of dye, and early vascular network and late staining hyperfluorescent plaque on ICGA. Two eyes with active neovascularization showed late-phase hyperfluorescence related to leakage on FA, and early vascular network and late staining hyperfluorescent plaque on ICGA. OCTA was performed in all eyes at least one examination. A neovascular complex was demonstrated on the OCTA en face projection image and flow signal on the cross-sectional OCTA in 3 eyes with active and in 7 eyes with quiescent neovascularization.

\section{Discussion}

In Best disease, the appearance of hyperreflectivity between the RPE and Bruch's membrane has been identified as fibrotic pillar, fibrotic nodule, fibrotic scar, or sub-RPE deposition in previous studies.[7-10] In the study by Kumar et al [7], 38 eyes of 19 patients with Best disease were evaluated, and 12 showed fibrotic pillars on OCT. It was reported that a subretinal hyporeflective space appeared in the pseudo-hypopyon stage and increased thereafter in the natural history of the disease. Then, fibrosis of subretinal vitelliform material occurred and localized vitelliform deposits and their fibrosis caused fibrotic pillars over time.[7] However, the vitelliruptive phase led to atrophy and fibrotic scarring, and fibrotic pillars occurred after a period of time. In our study, interestingly, those lesions were the presentation finding in 9 eyes of 5 patients at the mean age of 9.4 years (range, 7-13). In previous studies, vitelliform-stage disease was not detected at the time of examination, and sometimes did not occur, which is compatible with our finding.

It is known that these lesions have a relatively good prognosis. In the study of Zatreanu et al [3], 26 eyes of 13 patients with serous macular detachment with or without subretinal hyperreflective material were evaluated. Nine patients were incorrectly diagnosed as have central serous chorioretinopathy or age-related macular degeneration and had previously received multiple treatments, which were refractory to therapy and then therapies were deferred; 4 patients were then not treated. At last follow-up, patients' visual acuity and retinal status remained unchanged. None of the eyes in their study displayed any signs of retinal hemorrhage or intraretinal fluid. In our study 13 of 27 eyes with sub-RPE hyperreflectivity and serous macular detachment were followed up for 1 to 11 years after diagnosis. Similar to the previous report [3], visual acuity and retinal lesions were stable in 12 of 13 eyes (92\%) at last follow-up.

One issue in Best disease is active neovascularization. As the vitelliruptive phase leads to atrophy and fibrotic scarring, hemorrhage, either isolated or in association with neovascularization, may simulate the appearance of scar tissue.[4] However, active neovascularization can be differentiated from these lesions indirectly according to good response of treatment, or on multimodal imaging features such as hemorrhage on fundus image, intraretinal fluid on SD$\mathrm{OCT}$, increased hyperfluorescence related to leakage on FA, early network and late staining hyperfluorescent plaque on ICGA, and neovascular complex and flow on OCTA. These are helpful for correct diagnosis. In the study by Khan et al [11], 14 eyes of 12 patients with neovascularization complicating BEST-1related retinopathy were identified. It was reported that active treatment with intravitreal anti-VEGF agents was associated with better functional outcomes than observation alone. In our study, active neovascularization was identified in 3 (11\%) eyes on multimodal imaging and treatment was recommended. But our follow-up examination and treatment results are not available.

The similar appearance of sub-RPE epithelium hyperreflective material and quiescent neovascularization on fundus image and SD-OCT image is another issue. In some previous studies, the hyperreflective material between the RPE and Bruch's membrane was described as neovascularization. [3,12,13] However, not all highly reflective RPE elevations have an accompanying vascular network, and quiescent neovascularization can be distinguished from both these hyperreflective lesions easily by dye-based angiography and OCTA. In our study, in 17 of 27 eyes (63\%), no neovascular network was seen on OCTA or ICGA and all those eyes were identified as fibrosis. Seven eyes (26\%) with no hemorrhage on fundus image or no sign of activity except macular detachment on SDOCT were classified as quiescent neovascularization based on OCTA and /or ICGA. No unnecessary treatment was offered for those eyes.

Kumar et al [7] concluded that histopathological examination of eyes in vitelliruptive stages also had fibrous scarring in accordance with the OCT appearance of the fibrotic pillar.[7,14] It is also known that vitelliform lesions show hyperautofluorescence, but areas of atrophy and fibrosis show low or absent autofluorescence signal on fundus autofluorescence imaging.[9] In the light of this information, the hyperreflectivity between the RPE and Bruch's membrane on SD-OCT can be classified as fibrotic pillar, fibrotic nodule, or fibrotic scar if the lesion is hypoautofluorescent on fundus autofluorescence imaging and if there is no finding of neovascularization. In our study, the hyperreflective lesion was hypoautofluorescent on fundus autofluorescence image in 20 of 24 eyes with regular and hyperreflective RPE elevation.

Fibrotic pillars also play a role in the formation of focal choroidal excavations. Kumar et al [7] reported that 8 of 12 eyes (66\%) with fibrotic pillar had focal choroidal excavation directly beneath (33\%) or in close approximation (33\%) to the fibrotic pillar. It was concluded that fibrotic pillars lead to development of focal choroidal excavation. In our study, we also found focal choroidal excavation directly beneath the fibrotic pillar in 8 eyes (30\%), a similar result.

In conclusion, in Best disease, hyperreflective RPE elevation on SD-OCT may represent fibrosis, quiescent neovascularization, or active neovascularization, and multimodal imaging techniques are very important for differentiation of these lesions.

\section{Declarations}

\section{Disclosure and Acknowledgments}

a.Funding/Support: This research received no specific grant from any funding agency in the public, commercial, or not-for-profit sectors.

b.Financial Disclosure: No payment or services have been received from a third party for any aspect of the submitted work, including design, data collection, analysis, or interpretation of the data, writing of the report, or in the decision to submit the article for publication 


\section{References}

1. MacDonald IM, Lee T. Best vitelliform macular dystrophy. 2003 Sep 30 [Updated 2013 Dec 12]. In: Adam MP, Ardinger HH, Pagon RA, et al., editors. GeneReviews [Internet]. Seattle (WA): University of Washington, Seattle;1993-2019.

2. Schachat AP, Wilisoson CP, Hinton DR., et al. Ryan's Retina 6th edition, Elsevier (2018).

3. Zatreanu L, Freund KB, Leong BCS, Yu HG, Teke MY, Yzer S, et al. Serous macular detachment in best disease. A masquerade syndrome. Retina 2020;40:1456-1470

4. Qian CX, Charran D, Strong CR, Steffens TJ, Jayasundera T, Heckenlively JR. Optical coherence tomography examination of the retinal pigment epithelium in Best vitelliform macular dystrophy. Ophthalmology 2017;124:456-463.

5. Carnevali A, Cicinelli MV, Capuano V, Corvi F, Mazzaferro A, Querques L, et al. Optical Coherence Tomography Angiography: A Useful Tool for Diagnosis of Treatment Naïve Quiescent Choroidal Neovascularization. Am J Ophthalmol. 2016;169:189-198.

6. Karacorlu M, Sayman Muslubas I, Arf S, Hocaoglu M, Ersoz MG. Membrane patterns in eyes with choroidal neovascularization on optical coherence tomography angiography. Eye (Lond). 2019;33:1280-1289.

7. Kumar V, Chatra K. Fibrotic pillar leads to focal choroidal excavation in Best vitelliform dystrophy. Graefes Arch Clin Exp Ophthalmol. 2018;256:20832087.

8. Kay CN, Abramoff MD, Mullins RF, Kinnick TR, Lee K, Eyestone ME, et al. Three-dimensional distribution of the vitelliform lesion, photoreceptors, and retinal pigment epithelium in the macula of patients with best vitelliform macular dystrophy. Arch Ophthalmol. 2012;130:357-64.

9. Lima de Carvalho JR Jr, Paavo M, Chen L, Chiang J, Tsang SH, Sparrow JR. Multimodal Imaging in Best Vitelliform Macular Dystrophy. Invest Ophthalmol Vis Sci. 2019;60:2012-2022

10. Arora R, Khan K, Kasilian ML,Strauss RW, Holder GE, Robson AG, et al. Unilateral BEST-1 associated retinopathy. Am J Ophthalmol 2016;169:24-32.

11. Khan KN, Mahroo OA, Islam F, Webster AR, Moore AT, Michaelides M. Functional and anatomical outcomes of choroidal neovascularization complicating Best-1 related retinopathy. Retina 2017;37:1360-1370

12. Shahza R, Siddiqui MAR. Choroidal neovascularization secondary to Best vitelliform macular dystrophy detected by optical coherence tomography angiography. Journal of AAPOS 2017;21:68-70.

13. Alisa-Victoria K, Jin-Poi T, Shatriah I, Zunaina E, Ngah NF. Choroidal neovascularization secondary to Best's vitelliform macular dystrophy in two siblings of a Malay family. Clin Ophthalmol 2014;8:537-542.

14. O'Gorman S, Flaherty WA, Fishman GA, Berson EL. Histopathologic findings in Best's vitelliform macular dystrophy. Arch Ophtahlmol 1998;106:12611268.

\section{Tables}

Table 1. Demographic and clinical characteristics. 


\begin{tabular}{|c|c|c|c|c|c|c|c|c|c|c|c|c|c|}
\hline No & Sex & Eye & $\mathrm{Age}^{1}$ & BCVA & $\begin{array}{l}\text { Initial OCT } \\
\text { findings }\end{array}$ & $\begin{array}{l}\text { FA/ICGA } \\
\text { findings }\end{array}$ & Treatment & $\mathrm{FU}^{2}$ & $\begin{array}{l}\text { Final } \\
\text { BCVA }\end{array}$ & $\begin{array}{l}\text { Final } \\
\text { age }\end{array}$ & $\begin{array}{l}\text { Final OCT } \\
\text { findings }\end{array}$ & $\begin{array}{l}\text { OCTA } \\
\text { findings }\end{array}$ & Diag \\
\hline \multirow[t]{2}{*}{1} & $M$ & $\mathrm{R}$ & 12 & 0 & $\begin{array}{l}\text { SMD, SHL } \\
\text { inferior to fovea }\end{array}$ & NA & No & 14 & 0.2 & 26 & $\begin{array}{l}\text { SMD, SHL } \\
\text { inferior to fovea }\end{array}$ & $\begin{array}{l}\text { No } \\
\text { vascular } \\
\text { network }\end{array}$ & Fibrc \\
\hline & & $\mathrm{L}$ & & 1 & $\begin{array}{l}\text { SMD, SHL at } \\
\text { the fovea }\end{array}$ & NA & No & 14 & 1 & & $\begin{array}{l}\text { SMD, SHL at } \\
\text { the fovea }\end{array}$ & $\begin{array}{l}\text { No } \\
\text { vascular } \\
\text { network }\end{array}$ & Fibrc \\
\hline \multirow[t]{2}{*}{2} & $M$ & $\mathrm{R}$ & 7 & 0 & SMD & & No & 14 & 0.1 & 21 & SMD & & \\
\hline & $M$ & $\mathrm{~L}$ & 7 & 1 & $\begin{array}{l}\text { SMD, SHL at } \\
\text { the fovea }\end{array}$ & NA & No & 14 & 1 & 21 & $\begin{array}{l}\text { SMD, SHL at } \\
\text { the fovea }\end{array}$ & $\begin{array}{l}\text { No } \\
\text { vascular } \\
\text { network }\end{array}$ & Fibrc \\
\hline \multirow[t]{2}{*}{3} & $\mathrm{~F}$ & $\mathrm{R}$ & 43 & 0.4 & $\begin{array}{l}\text { SMD, SHL at } \\
\text { the fovea, CE, } \\
\text { ORD }\end{array}$ & $\begin{array}{l}\text { Quiescent } \\
\mathrm{NV}^{3}\end{array}$ & No & 8 & 0.4 & 51 & $\begin{array}{l}\text { SMD, SHL at } \\
\text { the fovea, CE, } \\
\text { ORD }\end{array}$ & $\begin{array}{l}\text { Vascular } \\
\text { network }\end{array}$ & $\begin{array}{l}\text { Quie } \\
\text { NV }\end{array}$ \\
\hline & & $\mathrm{L}$ & & 0.2 & $\begin{array}{l}\text { SMD, SHL } \\
\text { nasal to fovea }\end{array}$ & Fibrosis $^{4}$ & No & 8 & 0.2 & & $\begin{array}{l}\text { SMD, SHL } \\
\text { nasal to fovea }\end{array}$ & $\begin{array}{l}\text { No } \\
\text { vascular } \\
\text { network }\end{array}$ & Fibrc \\
\hline \multirow[t]{2}{*}{4} & $M$ & $\mathrm{R}$ & 24 & 0.5 & $\begin{array}{l}\text { SMD, SHL } \\
\text { inferior and } \\
\text { nasal to fovea }\end{array}$ & NA & No & - & - & - & - & $\begin{array}{l}\text { No } \\
\text { vascular } \\
\text { network }\end{array}$ & Fibrc \\
\hline & & $\mathrm{L}$ & & 1 & $\begin{array}{l}\text { SMD, SHL at } \\
\text { the fovea }\end{array}$ & NA & No & - & - & - & - & $\begin{array}{l}\text { No } \\
\text { vascular } \\
\text { network }\end{array}$ & Fibrc \\
\hline \multirow[t]{2}{*}{5} & $M$ & $\mathrm{R}$ & 24 & 0.4 & $\begin{array}{l}\text { SMD, subretinal } \\
\text { hyperreflectivity, } \\
\text { SHL at the } \\
\text { fovea }\end{array}$ & $\begin{array}{l}\text { Active } \\
\mathrm{NV}^{5}\end{array}$ & Yes & - & - & - & - & $\begin{array}{l}\text { Vascular } \\
\text { network }\end{array}$ & Activ \\
\hline & & $\mathrm{L}$ & & 0.1 & $\begin{array}{l}\text { SMD, SHL } \\
\text { inferior and } \\
\text { temporal to } \\
\text { fovea }\end{array}$ & Fibrosis 4 & No & - & - & - & - & $\begin{array}{l}\text { No } \\
\text { vascular } \\
\text { network }\end{array}$ & Fibrc \\
\hline \multirow[t]{2}{*}{6} & $M$ & $\mathrm{R}$ & 13 & 0.1 & $\begin{array}{l}\text { SMD, SHL } \\
\text { inferior and } \\
\text { temporal to } \\
\text { fovea }\end{array}$ & NA & No & 6 & 0.5 & 19 & $\begin{array}{l}\text { SMD, subretinal } \\
\text { hyperreflectivity, } \\
\text { intraretinal } \\
\text { fluid, SHL at the } \\
\text { fovea }\end{array}$ & $\begin{array}{l}\text { Vascular } \\
\text { network }\end{array}$ & Activ \\
\hline & & $\mathrm{L}$ & & 0.8 & $\begin{array}{l}\text { SMD, SHL at } \\
\text { the fovea, CE, } \\
\text { ORD }\end{array}$ & NA & No & 6 & 0.8 & & $\begin{array}{l}\text { SMD, SHL at } \\
\text { the fovea, CE, } \\
\text { ORD }\end{array}$ & $\begin{array}{l}\text { Vascular } \\
\text { network }\end{array}$ & $\begin{array}{l}\text { Quie } \\
\text { NV }\end{array}$ \\
\hline \multirow[t]{2}{*}{7} & $M$ & $\mathrm{R}$ & 16 & 0.3 & $\begin{array}{l}\text { SMD, SHL } \\
\text { inferior and } \\
\text { temporal to } \\
\text { fovea, CE }\end{array}$ & $\begin{array}{l}\text { Quiescent } \\
\mathrm{NV}^{3}\end{array}$ & No & - & - & - & - & $\begin{array}{l}\text { Vascular } \\
\text { network }\end{array}$ & $\begin{array}{l}\text { Quie } \\
\text { NV }\end{array}$ \\
\hline & & $\mathrm{L}$ & & 1 & $\begin{array}{l}\text { SMD SHL at the } \\
\text { fovea, } \\
\text { intraretinal } \\
\text { fluid, CE, ORD }\end{array}$ & $\begin{array}{l}\text { Active } \\
\mathrm{NV}^{5}\end{array}$ & Yes & - & - & - & - & $\begin{array}{l}\text { Vascular } \\
\text { network }\end{array}$ & Activ \\
\hline \multirow[t]{2}{*}{8} & $\mathrm{~F}$ & $\mathrm{R}$ & 44 & 0.8 & $\begin{array}{l}\text { SMD, SHL } \\
\text { inferior and } \\
\text { temporal to } \\
\text { fovea, ORD }\end{array}$ & NA & No & - & - & - & - & $\begin{array}{l}\text { No } \\
\text { vascular } \\
\text { network }\end{array}$ & Fibrc \\
\hline & & $\mathrm{L}$ & & 0.4 & $\begin{array}{l}\text { SMD, SHL at } \\
\text { the fovea, ORD }\end{array}$ & NA & No & - & - & - & - & $\begin{array}{l}\text { No } \\
\text { vascular } \\
\text { network }\end{array}$ & Fibrc \\
\hline \multirow[t]{2}{*}{9} & $M$ & $\mathrm{R}$ & 20 & 0.3 & SMD & & No & & & & & & \\
\hline & & $\mathrm{L}$ & & 0,2 & $\begin{array}{l}\mathrm{SMD}, \mathrm{SHL} \\
\text { inferior to } \\
\text { fovea, CE }\end{array}$ & Fibrosis 4 & No & - & - & - & - & $\begin{array}{l}\text { No } \\
\text { vascular } \\
\text { network }\end{array}$ & Fibrc \\
\hline \multirow[t]{2}{*}{10} & $M$ & $\mathrm{R}$ & 30 & 0.2 & $\begin{array}{l}\text { SMD, SHL at } \\
\text { the fovea }\end{array}$ & NA & No & - & - & - & - & $\begin{array}{l}\text { No } \\
\text { vascular } \\
\text { network }\end{array}$ & Fibrc \\
\hline & & $\mathrm{L}$ & & 0.2 & $\begin{array}{l}\text { Vitelliform } \\
\text { stage }\end{array}$ & & No & & & & & & \\
\hline
\end{tabular}




\begin{tabular}{|c|c|c|c|c|c|c|c|c|c|c|c|c|c|}
\hline No & Sex & Eye & $\mathrm{Age}^{1}$ & BCVA & $\begin{array}{l}\text { Initial OCT } \\
\text { findings }\end{array}$ & $\begin{array}{l}\text { FA/ICGA } \\
\text { findings }\end{array}$ & Treatment & $\mathrm{FU}^{2}$ & $\begin{array}{l}\text { Final } \\
\text { BCVA }\end{array}$ & $\begin{array}{l}\text { Final } \\
\text { age }\end{array}$ & $\begin{array}{l}\text { Final OCT } \\
\text { findings }\end{array}$ & $\begin{array}{l}\text { OCTA } \\
\text { findings }\end{array}$ & Diag \\
\hline \multirow[t]{2}{*}{11} & $M$ & $\mathrm{R}$ & 7 & 0.3 & $\begin{array}{l}\text { SMD, SHL } \\
\text { superior and } \\
\text { nasal to fovea }\end{array}$ & $\begin{array}{l}\text { Quiescent } \\
\mathrm{NV}^{3}\end{array}$ & No & 15 & 0.3 & 22 & $\begin{array}{l}\text { SMD, SHL } \\
\text { superior and } \\
\text { nasal to fovea }\end{array}$ & $\begin{array}{l}\text { Vascular } \\
\text { network }\end{array}$ & $\begin{array}{l}\text { Quie } \\
\text { NV }\end{array}$ \\
\hline & & L & & 0.7 & $\begin{array}{l}\text { SMD, SHL at } \\
\text { the fovea }\end{array}$ & $\begin{array}{l}\text { Quiescent } \\
\mathrm{NV}^{3}\end{array}$ & No & 15 & 0.7 & & $\begin{array}{l}\text { SMD, SHL at } \\
\text { the fovea }\end{array}$ & $\begin{array}{l}\text { Vascular } \\
\text { network }\end{array}$ & $\begin{array}{l}\text { Quie } \\
\text { NV }\end{array}$ \\
\hline \multirow[t]{2}{*}{12} & $\mathrm{~F}$ & $\mathrm{R}$ & 33 & 0.3 & SMD, ORD & & No & 16 & 0.7 & 49 & SMD, ORD & & \\
\hline & $\mathrm{F}$ & L & 33 & 0,7 & $\begin{array}{l}\text { SMD, SHL at } \\
\text { the fovea, CE, } \\
\text { ORD }\end{array}$ & Fibrosis $^{4}$ & No & 16 & 0.7 & 49 & $\begin{array}{l}\text { SMD, SHL at } \\
\text { the fovea, CE, } \\
\text { ORD }\end{array}$ & $\begin{array}{l}\text { No } \\
\text { vascular } \\
\text { network }\end{array}$ & Fibrc \\
\hline \multirow[t]{2}{*}{13} & $M$ & $\mathrm{R}$ & 19 & 0.3 & $\begin{array}{l}\text { SMD, SHL } \\
\text { inferior and } \\
\text { nasal to fovea }\end{array}$ & Fibrosis $^{4}$ & No & 7 & 0.3 & 26 & $\begin{array}{l}\text { SMD, SHL } \\
\text { inferior and } \\
\text { nasal to fovea }\end{array}$ & $\begin{array}{l}\text { No } \\
\text { vascular } \\
\text { network }\end{array}$ & Fibrc \\
\hline & & L & & 0.2 & $\begin{array}{l}\text { SMD, SHL } \\
\text { inferior and } \\
\text { nasal to fovea }\end{array}$ & Fibrosis $^{4}$ & No & 7 & 0.2 & 26 & $\begin{array}{l}\text { SMD, SHL } \\
\text { inferior and } \\
\text { nasal to fovea }\end{array}$ & $\begin{array}{l}\text { No } \\
\text { vascular } \\
\text { network }\end{array}$ & Fibrc \\
\hline \multirow[t]{2}{*}{14} & $M$ & $\mathrm{R}$ & 42 & 0.7 & SMD & & No & 1 & 0.7 & 43 & SMD & & \\
\hline & $M$ & L & 42 & 0.2 & $\begin{array}{l}\text { SMD, SHL at } \\
\text { the fovea, CE, } \\
\text { ORD }\end{array}$ & Fibrosis $^{4}$ & No & 1 & 0.2 & 43 & $\begin{array}{l}\text { SMD, SHL at } \\
\text { the fovea, CE, } \\
\text { ORD }\end{array}$ & $\begin{array}{l}\text { No } \\
\text { vascular } \\
\text { network }\end{array}$ & Fibrc \\
\hline \multirow[t]{2}{*}{15} & $M$ & $\mathrm{R}$ & 8 & 0.4 & $\begin{array}{l}\text { SMD, SHL at } \\
\text { the fovea, CE }\end{array}$ & $\begin{array}{l}\text { Quiescent } \\
\mathrm{NV}^{3}\end{array}$ & No & - & - & - & - & $\begin{array}{l}\text { Vascular } \\
\text { network }\end{array}$ & $\begin{array}{l}\text { Quie } \\
\text { NV }\end{array}$ \\
\hline & & L & & 0.1 & $\begin{array}{l}\text { SMD, SHL } \\
\text { nasal to fovea }\end{array}$ & $\begin{array}{l}\text { Quiescent } \\
\mathrm{NV}^{3}\end{array}$ & No & - & - & - & - & $\begin{array}{l}\text { Vascular } \\
\text { network }\end{array}$ & $\begin{array}{l}\text { Quie } \\
\text { NV }\end{array}$ \\
\hline \multirow[t]{2}{*}{16} & $\mathrm{~F}$ & $\mathrm{R}$ & 21 & 0.2 & $\begin{array}{l}\text { SMD, SHL at } \\
\text { the fovea }\end{array}$ & Fibrosis $^{4}$ & No & - & - & - & - & $\begin{array}{l}\text { No } \\
\text { vascular } \\
\text { network }\end{array}$ & Fibrc \\
\hline & & L & & 0.3 & $\begin{array}{l}\text { SMD, SHL at } \\
\text { the fovea }\end{array}$ & Fibrosis $^{4}$ & No & - & - & - & - & $\begin{array}{l}\text { No } \\
\text { vascular } \\
\text { network }\end{array}$ & Fibrc \\
\hline
\end{tabular}

1 Age at diagnosis, years

2 Time between diagnosis and last follow-up, years.

3 Early hypofluorescence and late hyperfluorescence on FA staining and hypofluorescence on ICGA.

4 Late-phase increased hyperfluorescence related to leakage on FA, and early vascular network and late staining hyperfluorescent plaque on ICGA.

5 Late-phase ill-defined hyperfluorescence on without pooling of dye on FA, and early vascular network and late-staining hyperfluorescent plaque on ICGA.

BCVA: Best corrected visual acuity

CE: Choroidal excavation

FA: Fluorescein angiography

FU: $\quad$ Follow-up, year

ICGA: Indocyanine green angiography

NA: No available data

NV: Neovascularization

OCT: Optical coherence tomography

ORD: Outer retinal damage

SHL: Subretinal pigment epithelium hyperreflective lesion

SMD: Serous macular detachment 


\section{Figures}
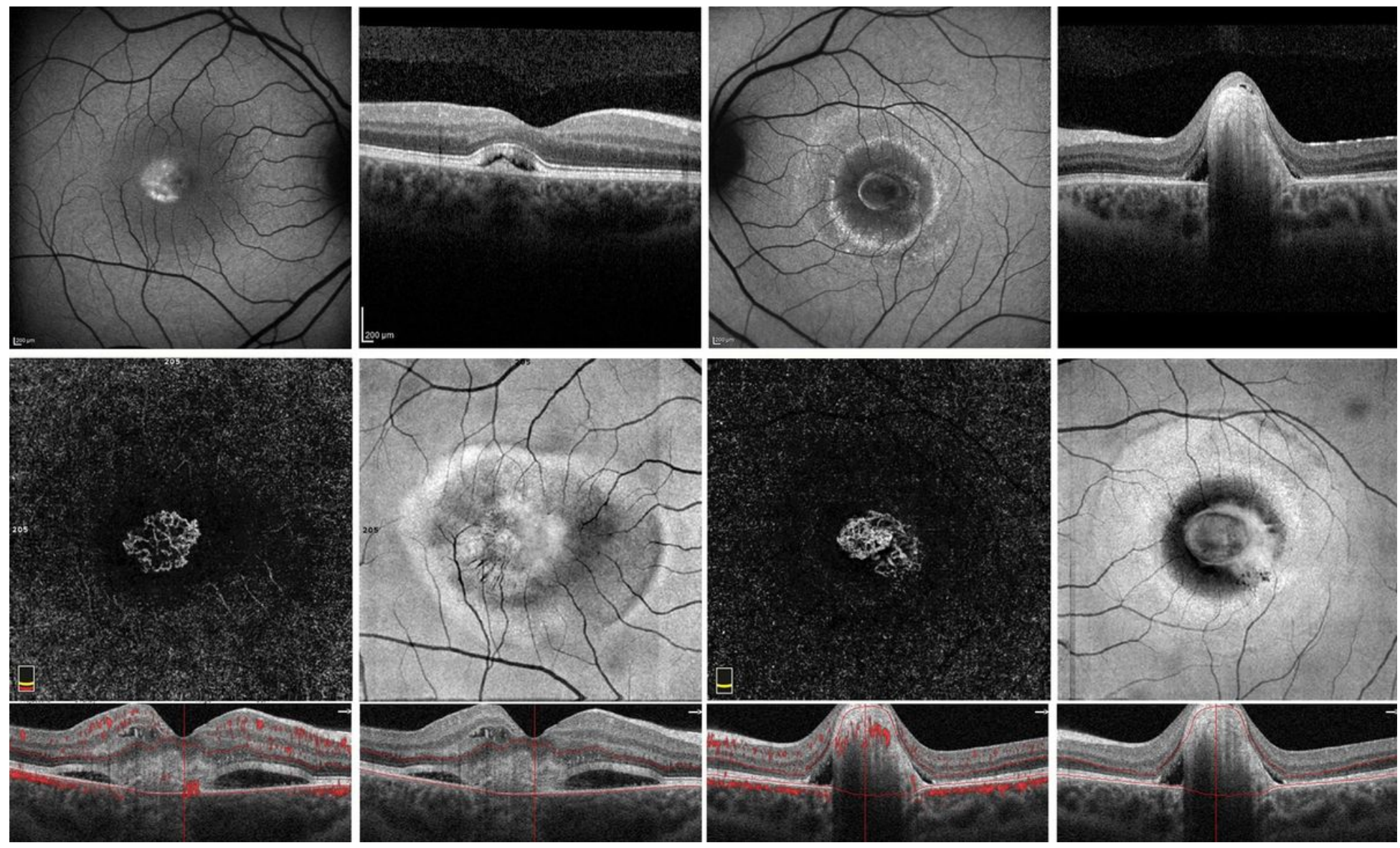

Figure 1

Multimodal imaging of the both eyes of a 13-year-old male patient. Fundus autofluorescence image identifies an area of central hyperautofluorescence in the right eye (A), and SD-OCT image identifies a small hyperreflective elevation of retinal pigment epithelium at the fovea with serous macular detachment in the same eye (B). A hypoautofluorescent round area at the center of fovea with a hyperautofluorescent rim in the left eye on fundus autofluorescence image(C), and regular and high hyperreflective elevation of retinal pigment epithelium on SD-OCT image in the same eye at presentation (D). The retinal status remained unchanged during a 6-year follow-up period in the left eye, and neovascularization developed in the right eye. At 6-year follow-up, optical coherence

tomography angiography images demonstrate an active neovascular complex in the right eye $(\mathrm{E}, \mathrm{F})$ and quiescent neovascularization in the left eye (G,H). No treatment was recommended for the left eye, and anti-VEGF injection was advised for the right eye. 


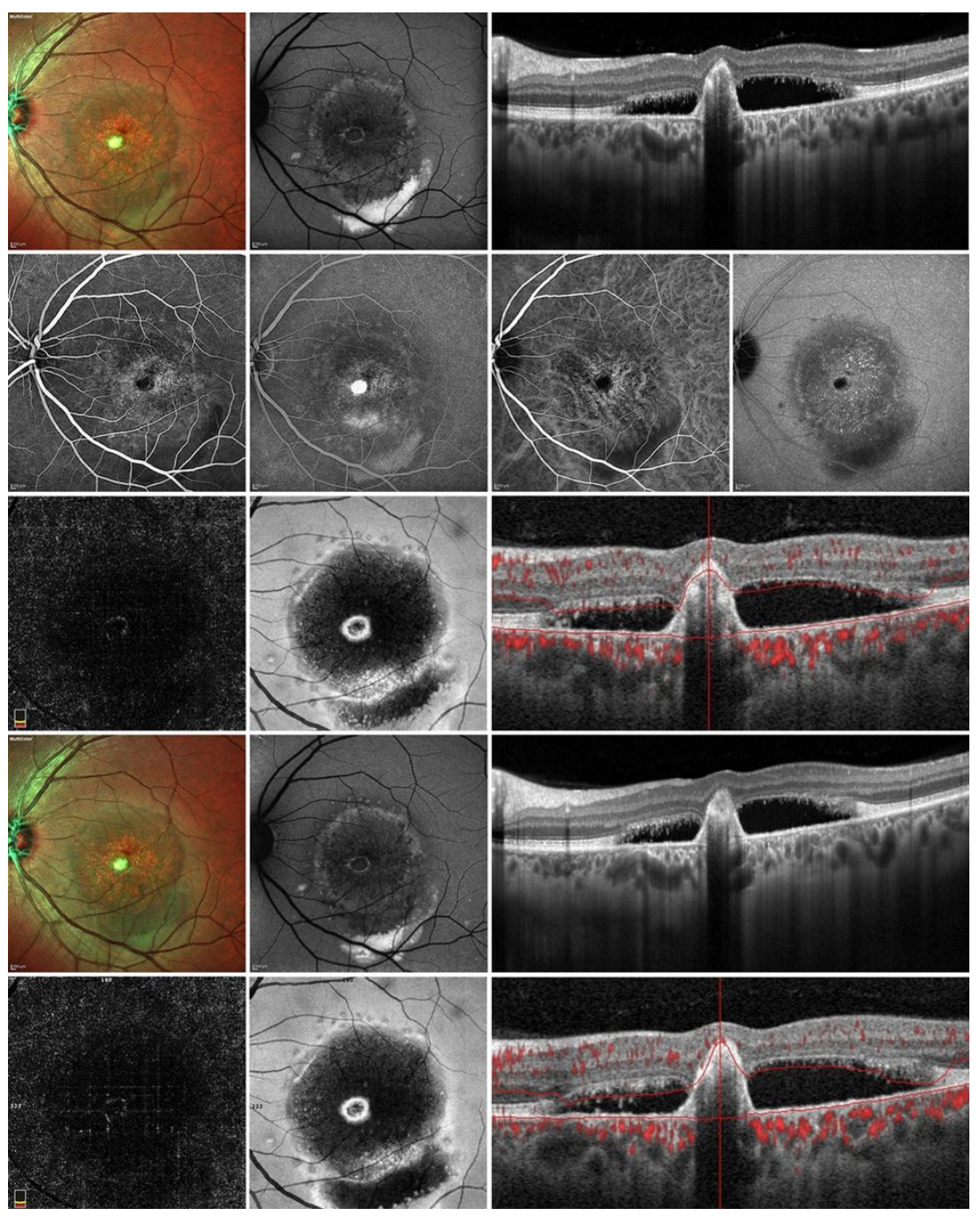

\section{Figure 2}

Multimodal imaging of the right eye of a 42-year-old male patient with subretinal fibrosis. Multicolor image shows central macular elevation, vitelliform material accumulation, and subretinal fibrosis inferonasal to the fovea (A). Fundus autofluorescence image demonstrates hypoautofluorescence with a hyperautofluorescent circle surrounding a small hypoautofluorescent ring around a hypofluorescent fovea, and a hyperfluorescent lesion in the inferior temporal macular area (B). Spectral-domain optical coherence tomography image illustrates regular hyperreflective elevation of retinal pigment epithelium inferior-nasal to the fovea, serous macular detachment, outer retinal damage, and choroidal excavation (C). Early-phase fluorescein angiography indicates an area of hypofluorescence inferior-nasal to the fovea and granular hyperfluorescence at the posterior pole (D). Late-phase fluorescein angiography indicates increased hyperfluorescence due to staining inferior-nasal to the fovea(E). Early-phase and late-phase indocyanine green angiography image demonstrate no neovascular network $(F, G)$. Optical coherence tomography angiography image demonstrates no neovascular complex (H,I,J). The patient's retinal status remained unchanged at 1-year follow-up (K-P, all images) 

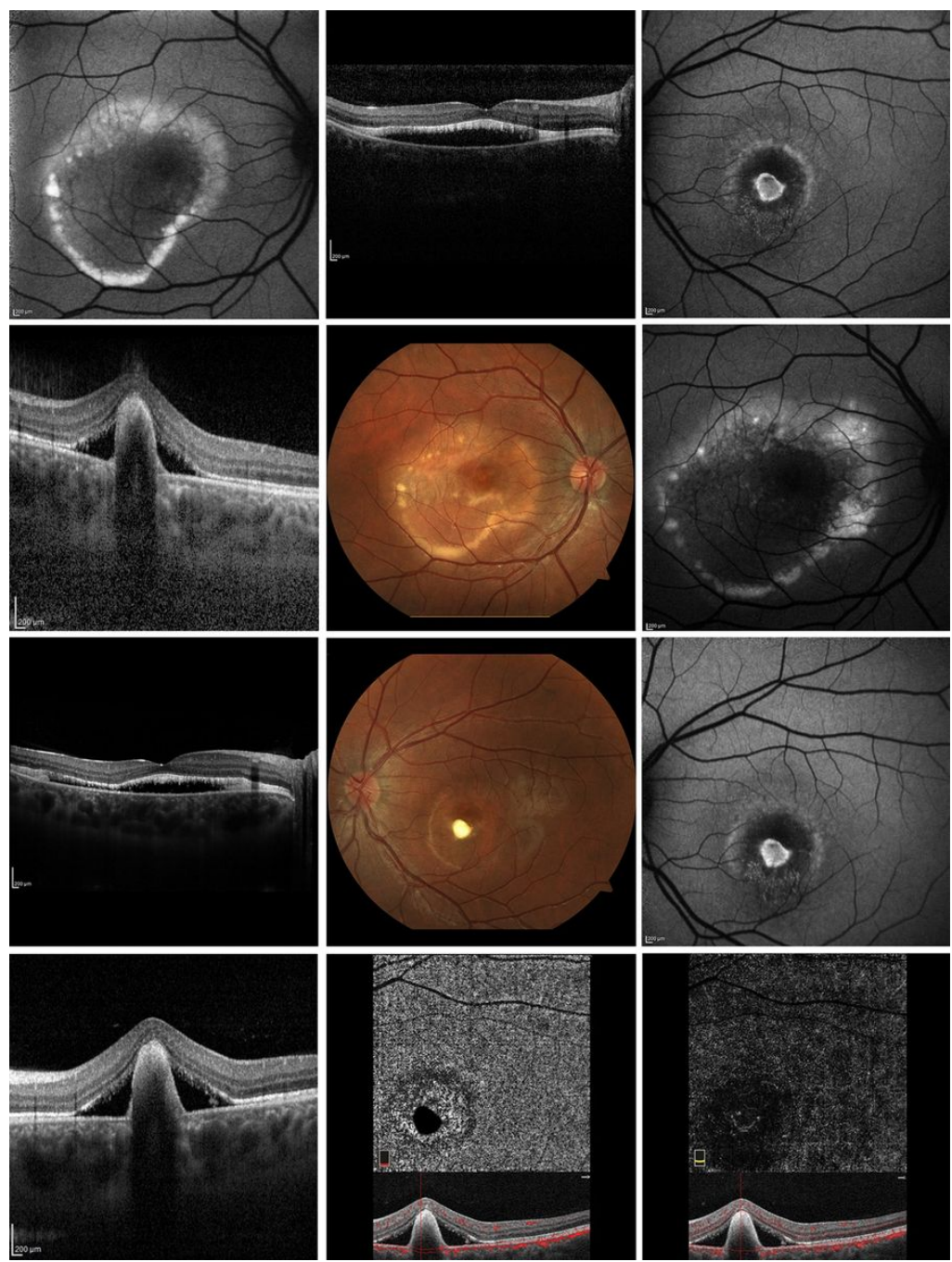

Figure 3

Multimodal imaging of both eyes of an 8-year-old male patient. Fundus autofluorescence image demonstrates central hypofluorescence and a hyperautofluorescent rim at the posterior pole, and SD-OCT image shows serous macular detachment in the right eye (A,B), and a central hyperautoflorescent area and a hyperautofluorescent rim at the posterior pole and a high, regular, hyperreflective elevation of retinal pigment epithelium in the left eye at presentation $(C, D)$. Eleven years after, color fundus image $(E, H)$, fundus autofluorescence image $(F, I)$, and SD-OCT image (G,J) demonstrate unchanged retinal status in both eyes. Both choriocapillaris $(\mathrm{K})$ and outer retinal slabs $(\mathrm{L})$ of optical coherence tomography angiography images confirm that neovascular complex does not exist at the last follow-up examination. 

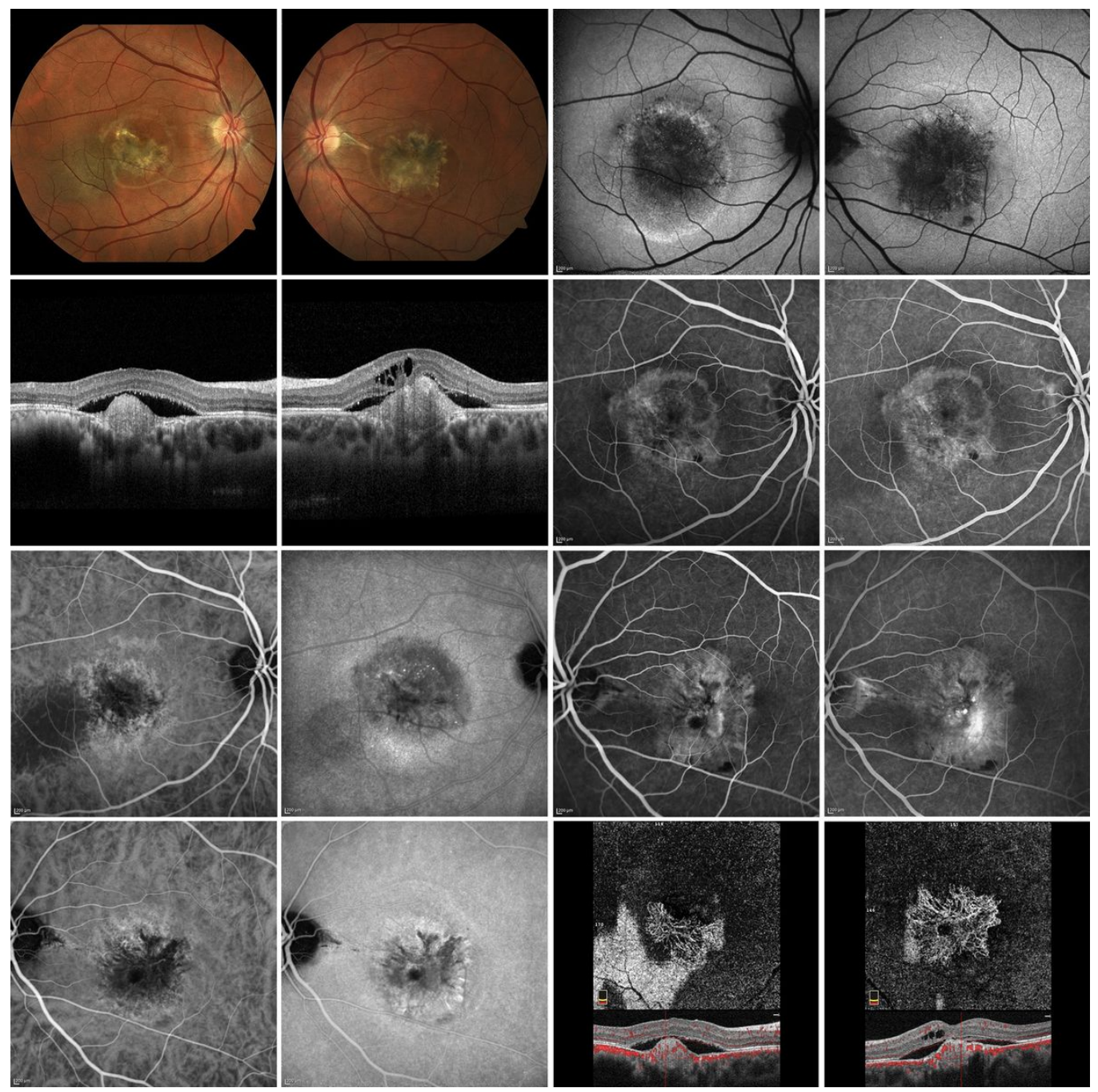

Figure 4

Multimodal imaging of both eyes of a 16-year-old male patient. Color images of both eyes show central macular elevation and vitelliform material accumulation at the posterior pole $(A, B)$. Fundus autofluorescence images identify an area of hypoautofluorescence at the fovea with a hyperautofluorescent rim in both eyes (C,D). SD-OCT images identify a regular hyperreflective elevation of retinal pigment epithelium, serous macular detachment, and choroidal excavation in both eyes and intraretinal cystic spaces in the left eye (E,F). Fluorescein angiography shows granular hyperfluorescence without a late leakage at the posterior pole and early vascular network and late irregular hypofluorescent and hyperfluorescent plaque on indocyanine green angiography (ICGA) in the right eye $(\mathrm{G}, \mathrm{H}, \mathrm{I}, \mathrm{J})$. In the left eye, a late phase increased hyperfluorescence on fluorescein angiography and early vascular network and late hypofluorescent and hyperfluorescent plaque on ICGA were seen $(\mathrm{K}, \mathrm{L}, \mathrm{M}, \mathrm{N})$. Optical coherence tomography angiography images also demonstrate neovascular complex in both eyes $(\mathrm{O}, \mathrm{P})$. No treatment was recommended for the right eye with quiescent neovascularization, and anti-VEGF injection was advised for the left eye with active leaking neovascularization. 